\title{
RELIABILITY OF INFORMATION SYSTEMS IN ORGANIZATIONS AS A FACTOR SHAPING ORGANIZATIONAL CULTURE
}

This paper analyses the potential relation between IS reliability and organizational culture. Based on the literature review, the research gap is identified and hypotheses concerning the potential role of IS in shaping organizational culture are proposed. The community-oriented culture is suggested as a potential direction of culture reorganization. The hypotheses are verified based on the empirical research performed in 2017 in 400 organizations in Poland. The research results indeed confirmed that IS can be considered as one of the factors shaping organizational culture. However, the direction of its change appeared to be different than the one presented in the current literature.

Keywords: information systems, IS reliability, organizational culture

JEL Classifications: M15, M20, M54

DOI: $10.15611 /$ aoe.2020.2.11

\section{INTRODUCTION}

Information systems (IS) reliability is a notion directly embedded in the user experience with IS in organizations and a new framework that allows for the more meaningful analysis of IS in organizations, which elides the outdated question: "Is the organization using an IS", and assumes the question which is more meaningful for modern organizations "Is the IS used in our organization good enough?". On the one hand, with the increase of IS reliability, there is an increase in employees' conviction that it will be beneficial for the organization and the employees themselves to use it. On the other hand, with the increase of IS reliability, its influence on the organization is more profound. Due to the fact that IS reliability is so closely connected to the employees and their role as IS users, it is important to determine what is the actual influence of IS and its reliability for those employees.

This paper aims to analyse the potential relation between IS reliability and organizational culture as one factor closely correlated with employees, their work environment and potential performance. It addresses a research gap in

* Faculty of Computer Science and Management, Wrocław University of Science and Technology. 
the literature, which broadly characterize the ways in which organizational culture influences the IS in organizations, but often disregards the fact that the opposite relation is also true and IS may be a factor influencing the culture in organizations. It is crucial to determine whether IS reliability influences the employees enough to shift the organizational culture due to the introduced reorganizations. Thus the main aim of this paper is to identify the relation between the type of organizational culture in the organization and the level of IS reliability and based on that conclude what may be the potential influence of IS reliability on organizational culture, and because of that - on the employees.

\section{IS RELIABILITY IN ORGANIZATIONS}

Organizations are managing a diverse portfolio of information systems' (IS) applications (Cummins, 2002) that are building the IT in organizations. Therefore, the notion of IT reliability is linked directly to the concept of IS reliability, and IT in an organization simply consists of all IS in this organization. That is why in many publications those two acronyms are used interchangeably. However, it is important to underline at the beginning that the reliability of IT or all IS in an organization is a different concept than the reliability of software or hardware, which are notions well known and broadly discussed in literature (Banker et al., 2002). Hence, it is crucial to not confuse it with those embedded directly in computer sciences, which do not include the IT management standpoint which is a crucial part for obtaining and retaining a competitive advantage from IT use in organizations.

Therefore, reliability of IS in organizations is understood as a measurable property of IS, useful for its control and management, identifying its quality level and pointing out potential problems (Zahedi, 1987) and it is directly linked to the efficiency of IS components, especially those critical to its proper operations. Therefore, it can be said that IS reliability in organizations is a notion built by factors connected to three different IS theories. The first one is the DeLone and McLean success model (DeLone and McLean, 2003), the second is Lyytinen (1987) with four types of IS failure, and the third one is the TAM model (Davis, 1985). Therefore, in order to fully develop the notion of IS reliability it is crucial to identify factors that are constructs for each of four identified variables proposed in the IS reliability model (see Figure 1). To identify all of them, a search of articles published from 2000 to 2018, with key words "IS in organization", "measurement", was conducted using the EBSCO and ProQuest databases. From all the available publications, those concerning lists of factors describing IS in an organization were purposefully selected. 


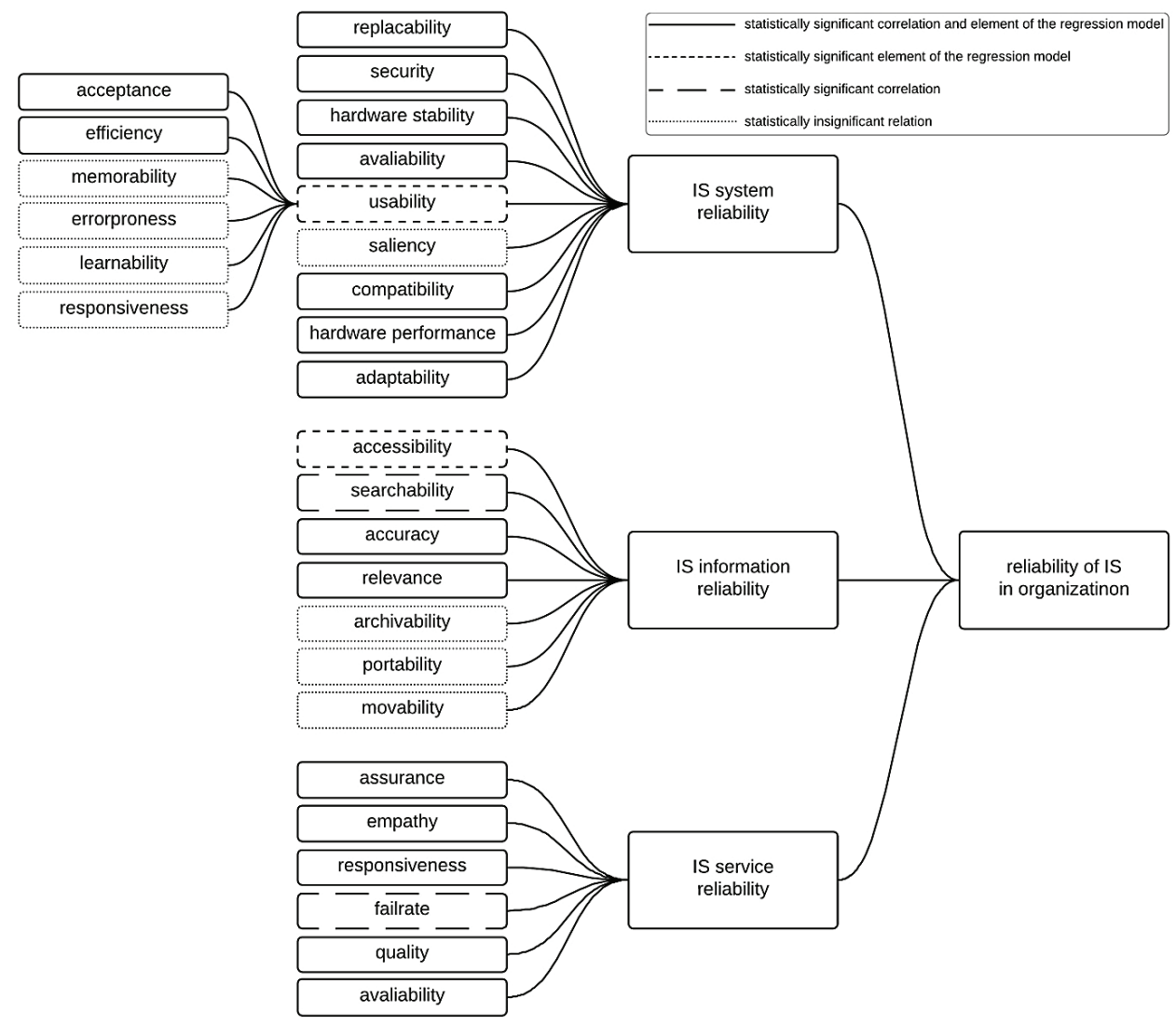

Fig. 1. Model of reliability of IS in an organization

Source: own work.

Based on the research (Niu et al., 2013; Palmius, 2007; Finne, 2005; Irani, 2002), all the factors potentially related to IS reliability in the context of the above-mentioned three IS theories were identified and assigned to the proposed four variables (Niu et al., 2013).

A model of IS reliability in an organization was developed, and a detailed description is published by Tworek (2019) and presented in Figure 1. The reliability of IS in an organization consists of four factors: the reliability of information included in IS in the organization, the reliability of support services offered for IS in the organization, and the reliability of the system itself, which also includes the usability of this system. Each factor is built by series of items listed on Figure 1. 
Moreover, based on the results of model testing, it can be said that reliable IT in an organization is characterized as (Tworek, 2019):

- IT, in which all IS have a short response time, and high availability connected with high security. However, the security should not be strained by the need for availability.

- IT, in which information is easily accessible, and its accuracy is guaranteed.

- IT, is in which all IS are accepted by its users and easy to use.

- IT, which has a responsive and available support services.

The model is the basis for measurement scales created for IT reliability analysed in this study. The corresponding items for measuring IT reliability are presented in Appendix 1.

\section{ORGANIZATIONAL CULTURE AND IS RELIABILITY}

There is a growing number of studies concerning cultural issues in the literature covering the field of information systems (IS) over the last few decades (Jackson, 2011; Leidner andKayworth, 2006). Organizational culture is usually listed as an important factor in the success or failure of information systems (IS) in organizations (Jackson, 2011). However, it can be said that even though those studies concern several different aspects of IS in organizations (development, adoption, use, management etc.), almost all of them concern in some way the notion of IS reliability stating that organizational culture somehow influences the user experience with the IS. Table 1 shows selected research articles concerning four aspects of organizational culture relations with IS in an organization. The authors provide several main conclusions, all related to the fact that there is a need to find an "IS-culture" to fit in every organization (Leidner and Kayworth, 2006).

First of all, it is not clear which type of culture will be the best choice for organizations trying to maximize their experience with IS use. Tomlin (1991) expressed his opinion about the concept of cultures oriented on information. Grover et al. (1998) concluded in the last century that cultures oriented on planning are better for organizations using IS. Harper and Utley (2001) suggested that organizational cultures that are oriented on people are known to create a better environment for IS adoption, use and management, than those oriented on production. However, Kanungo et al. (2001) stated that organizational cultures oriented on tasks are even better from the perspective of IS in an organization, suggesting that besides that, cultures oriented on innovation are the best choice for organizations, which underline the importance of IS. 
Secondly, it is not clear which culture values should be present in the organization in order to maximize the experience with IS use.

Table 1

Literature review concerning relation between organizational culture and IS

\begin{tabular}{l|l|l}
\hline \multicolumn{1}{c|}{ Main topic } & \multicolumn{1}{|c}{ Source } & \multicolumn{1}{c}{ Main conclusions } \\
\hline $\begin{array}{l}\text { Organizational } \\
\text { culture and IS } \\
\text { development }\end{array}$ & $\begin{array}{l}\text { Ngwenyama and } \\
\text { Nielsen (2003) }\end{array}$ & $\begin{array}{l}\text { The success of IS development is connected } \\
\text { with the fact that cultural values build into the } \\
\text { development methodologies should be shared by } \\
\text { both the development team and the main client. }\end{array}$ \\
\hline $\begin{array}{l}\text { Organizational } \\
\text { culture and IS } \\
\text { adoption }\end{array}$ & $\begin{array}{l}\text { Jackson (2011) } \\
\text { Huang et al. (2003) }\end{array}$ & $\begin{array}{l}\text { Those employees who are less comfortable with } \\
\text { the uncertainty and have a tendency to avoid it will } \\
\text { be less likely to adopt new IS in the organization. } \\
\text { The employees are more likely to adopt new IS in } \\
\text { the organization when their values are shared by } \\
\text { the concept of this IS system and the system itself. }\end{array}$ \\
\hline $\begin{array}{l}\text { Organizational } \\
\text { culture and IS } \\
\text { use }\end{array}$ & $\begin{array}{l}\text { Doherty and Doig } \\
\text { (2001) } \\
\text { Kanungo et al. } \\
\text { (2001) } \\
\text { Baitahazard and } \\
\text { Cooke (2003) }\end{array}$ & $\begin{array}{l}\text { There is a particular set of culture values, which is } \\
\text { shown in organizations, which present higher user } \\
\text { satisfaction and higher efficiency of IS use. }\end{array}$ \\
\hline $\begin{array}{l}\text { Organizational } \\
\text { culture and IS } \\
\text { management }\end{array}$ & Kaarst-Brown (1995) & $\begin{array}{l}\text { There are not many studies concerning this topic } \\
\text { (Leidner and Kayworth, 2006) and usually they } \\
\text { are focused on values and actual use. }\end{array}$ \\
\hline
\end{tabular}

Source: own work.

These literature findings may be considered as a source of important questions. Is it clear that the adopted organizational culture influences the IS in the organization (and its success), or whether this relation works both ways? There are some authors suggesting that IS in organizations changed the nature of task implementation in every company in such a profound way that it should be considered as the main factor influencing the social changes in organizations (Crowston, 2000; Cecez-Kecmanovic et al., 2014).

Considering the statement of Crowston (2000), that IS first and foremost impact on every organization is caused by reorganizing the communication channels within the organization (making it easier for employers to communicate directly), it seems logical to assume that this impact causes a shift in organizational culture. More confirmation can be found while considering other aspects of IS influence on organization, such as (Crowston, 2000; Tworek, 2019): 
- Reduction of the number of administrative employees and middle management employees mainly caused by a more efficient exchange of information.

- Increase of self-reliance due to better access to information among employees using IT, which contributes to the increase of the average span of management.

- Increase of information synergy on the lower levels of management, which leads to the situation in which employees are better equipped to make the right decisions in the place where the problem arises.

- Willingness among managers to delegate decisions to lower levels of the hierarchy due to the fact that employees acquire additional skills and knowledge while using IT.

- Emergence of the intelligent formalization effect, which allows employers to communicate and exchange information in a codified way, which ultimately contributes to the unification and organization of documents and procedures.

- Reduction of the negative effects of specialization due to work enrichment and increased self-reliance of employees.

It is clear that with the increase of IS reliability, employees become more inclined to use IS and the potential influence this has on organization is bigger (Tworek, 2019). Since the influence is directly linked to the employees' role and the tasks performed in the organization, it may be assumed that IS reliability has the potential to impact on the factors related to the employees such as organizational culture. Hence it may be concluded that IS reliability may be somehow correlated with the type of organization culture, or it may even influence a shift in organizational culture.

The direction of this shift is partially suggested by the researchers analysing the relation between organizational culture and IS in an organization, as above (Kanungo et al., 2001; Leidner and Kayworth, 2006). As mentioned, the authors are suggesting that the best fit for organizations which want to benefit from IS, are organizational cultures which enable employees to be innovative, cooperate and provide them with a flexible work environment.

Hopej et al. (2017) proposed an organizational structure continuum based on a few typical culture dimensions. At the one end of this continuum there are top-down cultures, where power, decisions, knowledge and culture itself are disseminated from the top of the organizational hierarchy to the bottom of it, and at the other end there are bottom-up cultures, disseminated from the bottom of the organizational hierarchy. The community-oriented culture, according to Hopej et al. (2017), is one of the extremes of the proposed continuum. This is a type of culture which favours the development of 
cooperation between employees, and can even be characterized as "bottom-up cooperation" or "self-organization". This culture is based on the assumption that employees have a natural predisposition to cooperate. Banker (2011) discussed the "gene of cooperation" together with a brief overview of the latest experiments. He suggested that people have a tendency for a "natural collaboration", which can be perceived as the third pillar of evolution, next to mutation and natural selection (Nowak, 2006). Hence, this kind of organizational culture seems to be a logical goal for an organization which wants to gain competitive advantage by using IS and from the positive influences of IS on organizations. This is not only because IS influence on organization concerns the reorganization of communication channels in order to establish platforms for mutual cooperation of employees, but also because it provides employees with the substantial validation of their role in the organization and empowers them to use the decision-making and knowledge sharing opportunities that reliable IS give them. Therefore, it may be concluded that reliable IS reorganizing the communication channels and workflows in organizations may be also a factor enabling them to adopt the communityoriented organizational culture.

Therefore, based on the literature review and the author's own reasoning presented in this paragraph, two hypotheses arise:

Hypothesis A: IS reliability is one of the factors influencing the organizational culture.

Hypothesis B: The more reliable IS in organization, the more communityoriented culture.

These hypotheses form the answer to the previously formulated question: yes, IS reliability may also influence the organizational culture, not just the other way round. These hypotheses were tested in order to verify the actual relation between the organizational culture and IS reliability in an organization.

\section{RESEARCH METHODOLOGY}

The survey was conducted in order to identify the level of IS reliability in organizations, organizational culture type (based on the community-oriented culture concept) and contextual variables (manufacturing technology, strategy, environment). The pilot survey was conducted in 2017 in the group of 100 organizations, indicating issues concerning the ambiguity of several questions. This led to a collection of random answers given as a response to those questions. They were rewritten in order to obtain more reliable results, ensuring an informed response from the respondent. The main survey was conducted later in 2017, among small and medium (SME) organizations 
located in Poland, using the online survey service, SurveyMonkey. Only one survey was carried out in one organization. The research was anonymous. Efforts were made to make sure that the questionnaire was filled in by employees with a broad view of the entire organization. The statistical population (SME operating in Poland) is finite, but very large. 400 valid responses were collected. Since the responses were collected using a properly prepared form, the online system counted only those fully and correctly filled in.

The respondents were asked to evaluate the IS in the organization based on the list of factors using the Likert scale (from very poor to very good with the middle point: fair). They were asked for their general opinion concerning reliability of system, usage, information and service, and then they were asked to evaluate each factor constructing those four variables. Using a Likert scale to measure IS reliability seems to be an appropriate choice. First of all, the reliability of IS in organizations is a subjective notion. Employees own perspective and opinion concerning aspects of IS reliability is the best source of knowledge, since their perception matters the most, that is because IS influences the organization mainly through its potential to influence the everyday work of the employees. Quantitative methods are commonly used to assess the software and hardware features linked to the reliability. However, they do not give the information concerning the actual perception of this notion within the organization.

The respondents were also asked to evaluate the organizational culture type based on the list of factors describing the community-oriented culture. The questions concerning the contextual variables were based on the standard questionnaires used for each of them. Appendix 1 presents all items relevant to the subject of this article analysed during the research.

\subsection{Research results}

The statistical analysis performed to test the presented hypotheses was based on several variables. IS reliability was measured using items forming IS system reliability, IS information reliability and IS service reliability. Overall IS reliability measure was also used for some statistical tests. Items characterizing organizational culture, structure, manufacturing technology and environment were also formed. The Cronbach's alpha analysis of scales were performed, confirming that scales for each variable were chosen correctly (see Table 2). 
Table 2

Cronbach's alpha analysis of scales

\begin{tabular}{l|c}
\hline \multicolumn{1}{c|}{ Variable } & Cronbach's alpha \\
\hline IS System reliability & 0.967 \\
\hline IS Information reliability & 0.931 \\
\hline IS Service reliability & 0.941 \\
\hline IS Usage reliability & 0.984 \\
\hline IS reliability & 0.931 \\
\hline Organizational structure & 0.824 \\
\hline Organizational culture & 0.709 \\
\hline Environment & 0.813 \\
\hline Manufacturing technology & 0.762 \\
\hline
\end{tabular}

Source: own work.

As a first step, correlation analysis was performed and is presented in Table 3 . The analysis shows that there is a statistically significant correlation between reliability of IS in an organization and organizational culture. However, considering the formation of each scale, it should be underlined that the correlation is a negative one. This means that the increase in IS reliability in organizations causes the decrease of the characteristics building the culture variable.

Table 3

Spearman correlation between variables

\begin{tabular}{|c|c|c|c|c|c|}
\hline \multirow{3}{*}{ IS reliability } & & Structure & Culture & Environment & $\begin{array}{c}\text { Manufacturing } \\
\text { technology }\end{array}$ \\
\hline & $r$ & $-.334^{* *}$ & $-.671^{* *}$ & $-.303^{* *}$ & $-.383^{* *}$ \\
\hline & $\mathrm{p}$ & $<0.01$ & $<0.01$ & $<0.01$ & $<0.01$ \\
\hline
\end{tabular}

Note: $\mathrm{r}$ - Spearman correlation; $\mathrm{p}$ - significance level; ** - correlation significant on the level of $\mathrm{p}<0.01$

Source: own work.

Next, in the course of the regression analysis, five models were obtained (see Table 4). The models were obtained for organizational culture as a dependent variable and IS reliability and contextual variables as independent ones. The best fitting model was obtained for IS system reliability, manufacturing technology and structure (adjusted $\mathrm{R}^{2}=0.552$ which means that 
those variables explain more than $50 \%$ of organizational culture variance) and are presented in Table 5. It is worth noting that similarly fitting model was obtained using those variables together with IS information reliability, which means that this aspect of IS reliability does not have a meaningful role in explaining the organizational culture variance.

Table 4

Regression models for organizational culture

\begin{tabular}{l|l|c|c|c|c}
\hline Model & \multicolumn{1}{|c|}{ Predictors } & $\mathrm{R}$ & $\mathrm{R}^{2}$ & Adjusted $\mathrm{R}^{2}$ & $\begin{array}{c}\text { Standard } \\
\text { error }\end{array}$ \\
\hline 1 & information reliability & $.543^{\mathrm{a}}$ & .295 & .293 & .53380 \\
\hline 2 & information reliability, structure & $.719^{\mathrm{b}}$ & .517 & .515 & .44233 \\
\hline 3 & $\begin{array}{l}\text { information reliability, structure, } \\
\text { manufacturing technology }\end{array}$ & $.737^{\mathrm{c}}$ & .543 & .539 & .43100 \\
\hline 4 & $\begin{array}{l}\text { information reliability, structure, } \\
\text { manufacturing technology, IS system } \\
\text { reliability }\end{array}$ & $.746^{\mathrm{d}}$ & .557 & & .552 \\
\hline 5 & $\begin{array}{l}\text { structure, manufacturing technology, } \\
\text { IS system reliability }\end{array}$ & $.746^{\mathrm{e}}$ & .557 & .553 & .42485 \\
\hline
\end{tabular}

Source: own work.

Table 5

The best fitting regression model for organizational culture

\begin{tabular}{l|c|c|c|c}
\hline & Coefficient & Standard error & $t$ statistic & $p$ value \\
\hline Constant & 2.093 & .111 & & 18.790 \\
\hline Structure & .345 & .042 & .364 & 8.137 \\
\hline Manufacturing technology & .185 & .040 & .210 & 4.667 \\
\hline IS system reliability & -.313 & .021 & -.498 & -14.830 \\
\hline
\end{tabular}

Source: own work.

Hence the results of the regression analysis confirm that at least one aspect of IS reliability (IS system reliability together with usage reliability) has a statistically significant influence on organizational culture. To further confirm this conclusion, an MCA analysis was performed (see Table 6). For each variable, the results were categorized based on standardized distribution into the Lower and Higher category. The results shown in Table 6 confirm that lower levels of IS reliability have a high discriminatory power over lower levels of organizational culture, and the same can be seen for higher levels, which confirms that indeed, IS reliability influences the culture in organization. 
Table 6

MCA analysis of relation between IS and organizational culture

\begin{tabular}{l|c|c|c|c|c|c}
\hline & & Coordinate & Coordinate & \multirow{2}{*}{ Quality } & R:L & R:H \\
\cline { 2 - 4 } \cline { 6 - 7 } & & 1 & 2 & & \multicolumn{2}{|c}{ Discriminatory power } \\
\hline \multirow{2}{*}{ IS reliability } & $4.6: \mathrm{L}$ & -1.23783 & -0.407095 & 0.637454 & $\mathbf{0 . 9 0 6}$ & 0.097 \\
\cline { 2 - 4 } & $4.6: \mathrm{H}$ & 0.46471 & 0.152834 & 0.637454 & 0.081 & 0.894 \\
\hline
\end{tabular}

Source: own work.

\subsection{Discussion}

The obtained results are sufficient for the verification process of the proposed hypotheses. Hypothesis A, which stated that IS reliability is one of the factors influencing the organizational culture was confirmed. There were three sources of this confirmation. The first was correlation analysis, which confirmed that there is a relation between those two notions, however it cannot be used to confirm the cause-effect relation. The second was regression analysis, which confirmed that some of the items characterized IS reliability in organization - IS system reliability together with IS usage reliability - is a statistically significant independent variable in the obtained, fitting model for the organizational culture. The third was an MCA analysis, which clearly confirmed that IS reliability as a whole concept influences the organizational culture. Based on all that, it can be assumed that IS reliability, especially the reliability of the system itself and the employees' perception of its use, is an important factor, which together with organizational structure and manufacturing technology influences the culture in organization. Therefore, the obtained results remain in line with the views presented in the literature and mentioned earlier, that IS have the ability to influence and shape the organizational culture.

Moreover, the confirmation of the first hypothesis allows for the cognitive logic process to go further to the verification of the second hypothesis. Hypothesis B, which stated that the more reliable the IS in the organization, the more community-oriented the culture, was disproved mainly based on the correlation and regression analysis. The correlation analysis clearly showed that the statistically significant correlation between IS reliability and organizational culture is negative (and the same occurred for every element of IS reliability: IS system reliability, IS usage reliability, IS information reliability, IS service reliability). This shows that the increase of IS reliability in organizations is correlated with the decrease of the organizational culture characteristics. Looking at the items building the organization culture variable 
(Appendix 1, it can be concluded that a decrease in them means that organizational culture is becoming less community-oriented. Therefore, this is a sufficient basis for disproving the proposed hypothesis and for concluding that the more reliable the IS in an organization, the less community-oriented its culture. This conclusion is also based on the fact that Hypothesis A was proved to be correct and it gives credence to the discussion concerning the nature of the confirmed relation between IS reliability and organizational culture.

\section{CONCLUSION}

The performed empirical research clearly shows that there is indeed a relation between organizational culture and IS in organizations. Moreover, it seems that the proposed research covers to some extent the identified theoretical gap. That is mainly because the research confirmed that IS reliability has the ability to influence culture in the organization. The role of IS system reliability, together with IS usage reliability proved to be especially important in the context of organizational culture. These two elements building IS reliability are closely related to the user experience with IS, and confirms the initial thought that IS reliability influences employees in the organization based on the mechanisms identified in the second section of this paper, which may even cause a shift in organizational culture.

The most interesting part of the conclusions that arose from the research is the direction in which IS reliability shifts the organizational culture. Based on the analysis, it can be concluded that it shifts the culture to solutions associated with top-down cultures, where power, decisions, knowledge and culture itself are disseminated from the top of the organizational hierarchy to the bottom of it. This conclusion is in opposition to the views presented in most literature findings. However, it is not without merit and may be closely connected to the confirmed mechanism, which causes IS in an organization to change the information and communication flows and makes them more efficient, have more bandwidth and be more reliable. All this suggests that it is easier and faster to disseminate power, knowledge and decisions throughout the entire organization when there is a reliable IS in it. It can be also seen as evidence that IS can influence an organization in many ways and many directions. The previously mentioned quicker propagation and deeper penetration of information throughout the organization may indeed influence a shift in organizational culture. However, it is important to underline that the shift is not necessarily directed at allowing the employees to use their natural 
predisposition to cooperate - as proposed by most research findings, but may be also be directed to more centralized organizational solutions. This assumption can be further confirmed by the analysis of the role of structure - a contextual variable, which was also a statistically significant variable in the regression model. It is also negatively, statistically significantly correlated with IS reliability, which confirms that the increase of centralization is connected with the increase of IS reliability.

It is important to underline that the presented research has its limitations, being based on the sample of 400 organizations operating in Poland and further verification in different business contexts is required. Moreover, only one aspect of organizational culture was tested. Although the research presented here is a firm first step in the process of verification of the relation between culture and IS reliability, different organizational culture types should be considered next. This should be done taking into account the obtained results and the next research project should include not only bottom-up cultures preferred in modern literatures, but also their opposites. However, it can be concluded that the obtained results are a concrete addition to the field of study concerning the relation between IS in organizations and organizational culture, presenting a point of view not yet present in the current literature.

\section{REFERENCES}

Balthazard, P. A., Cooke R. A. Organizational culture and knowledge management success: assessing the behavior-performance continuum [in:] 37th Annual Hawaii International Conference on System Sciences, 2004. Proceedings of the, pp. 10-pp. IEEE, 2004.

Benker, Y., The unselfish gene, "Harvard Business Review", pp. 76-85, 2011.

Bresnahan, T., Brynjolfsson, E., Hitt, L., IT, Workplace Organization and the Demand for Skilled Labor: A Firm-level Analysis, Mimeo, Stanford, 2000.

Cecez-Kecmanovic, D., Galliers, R. D., Henfridsson, O., Newell, S., Vidgen, R., The sociomateriality of information systems: current status, future directions, "MIS Quarterly", 38(3), pp. 809-830, 2014.

Crowston, K., Processes as theory in information systems research, Arlborg, Germany, International Working Conference on the Social and Organizational Perspective on Research and Practice in Information Technology, 2000.

Doherty, N. F., Doig, G., An Analysis of the Anticipated Cultural Impacts of the Implementation of Data Warehouses, "IEEE Transactions on Engineering Management" 50(1), pp. 78-88, 2003.

Doherty, N. F., Perry, I., The Cultural Impact of Workflow Management Systems in the Financial Services Sector, "The Services Industry Journal” 21(4), pp. 147-166, 2001.

Grover, V., Teng, J. T. C., Fiedler, K. D., IS Investment Priorities in Contemporary Organizations, "Communications of the ACM" 41(2), pp. 40-48, 1998. 
Harper, G. R., Utley, D. R., Organizational Culture and Successful Information Technology Implementation, "Engineering Management Journal" 13(2), pp. 11-15, 2001.

Hopej, M., Kamiński, R., Tworek, K., Walecka-Jankowska, K., Zgrzywa-Ziemak, A., Community-oriented culture and simple organizational structure, "Organization and Management" 4A, pp. 75-92, 2017.

Huang, J. C., Newell. S., Galliers, R., Pan. S. L., Dangerous Liaisons? Component Based Development and Organizational Subcultures. "IEEE Transactions on Engineering Management" 50(1). pp. 89-99, 2003.

Jackson, S., Organizational culture and information systems adoption: A three-perspective approach. "Information and Organization", 21(2), 57-83, 2011.

Kaarst-Brown, M. L., A Theory of Information Technology Cultures: Magic Dragons. Wizards and Archetypal Patterns, unpublished doctoral dissertation, York University, Toronto, Canada, 1995.

Kanungo, S., Sadavarti, S., Srinivas, Y., Relating IT Strategy and Organizational Culture: An Empirical Study of Public Sector Units in India. "Journal of Strategic Information Systems" 10(1), pp. 29-57, 2001.

Leidner, D. E., Kayworth, T., A review of culture in information systems research: Toward a theory of information technology culture conflict, "MIS quarterly", 30(2), pp. 357-399, 2006.

Ngwenyama, O., Nielsen, P. A., Competing Values in Software Process Improvement: An Assumption Analysis of CMM from an Organizational Culture Perspective, "Transactions on Engineering Management" 50(1), pp. 101-111, 2003.

Nowak, M., Five rules for the evolution of cooperation, "Science", 314(5805), pp. 1560-1563, 2003.

Tomlin, R., Developing a Management Climate Culture in Which Information Technology Will Flourish: How the UK Can Benefit, "Journal of Information Technology" 6, pp. 45-55, 1991.

Tworek, K., Aligning IT with Business. Springer, Cham 2019.

Received: April 2018 


\section{APPENDIX 1}

Please evaluate practices concerning information systems in your company.

\begin{tabular}{l|l|l|l|l|l}
\hline & $\begin{array}{c}\text { I strongly } \\
\text { agree }\end{array}$ & I agree & $\begin{array}{c}\text { I do not } \\
\text { have an } \\
\text { opinion }\end{array}$ & I disagree & $\begin{array}{c}\text { I strongly } \\
\text { disagree }\end{array}$ \\
\hline $\begin{array}{l}\text { Reliability of information systems in } \\
\text { the organization is sufficient in my } \\
\text { opinion. }\end{array}$ & & & & & \\
\hline $\begin{array}{l}\text { Decisions about investing in } \\
\text { information systems in organization } \\
\text { are uncoordinated. }\end{array}$ & & & & & \\
\hline $\begin{array}{l}\text { Decisions about investing in } \\
\text { information systems in organization } \\
\text { are made after key components are } \\
\text { identified and documented (in case } \\
\text { of costs and benefits). }\end{array}$ & & & & & \\
\hline $\begin{array}{l}\text { Decisions about investing in } \\
\text { information systems in organization } \\
\text { are based on objective project } \\
\text { selection. }\end{array}$ & & & & & \\
\hline $\begin{array}{l}\text { Decisions about investing in } \\
\text { information systems in organization } \\
\text { are aligned with business strategy. }\end{array}$ & & & & & \\
\hline
\end{tabular}

Please evaluate the below-mentioned features of information system (both software and hardware) in your company.

\begin{tabular}{l|l|l|l|l|l}
\hline & $\begin{array}{c}\text { Very } \\
\text { poor }\end{array}$ & Poor & Fair & Good & $\begin{array}{c}\text { Very } \\
\text { good }\end{array}$ \\
\hline usability & & & & & \\
\hline security & & & & & \\
\hline hardware stability & & & & & \\
\hline availability & & & & & \\
\hline replicability & & & & & \\
\hline saliency & & & & & \\
\hline compatibility & & & & & \\
\hline adaptability & & & & & \\
\hline usability & & & & & \\
\hline security & & & & & \\
\hline
\end{tabular}


Please evaluate the below-mentioned features of information system usability in your company.

\begin{tabular}{l|l|l|l|l|l}
\hline & $\begin{array}{l}\text { Very } \\
\text { poor }\end{array}$ & Poor & Fair & Good & $\begin{array}{c}\text { Very } \\
\text { good }\end{array}$ \\
\hline learnability & & & & & \\
\hline memorability & & & & & \\
\hline efficiency & & & & & \\
\hline acceptance & & & & & \\
\hline responsiveness & & & & & \\
\hline error proneness & & & & & \\
\hline
\end{tabular}

Please evaluate the below-mentioned features of information in your company's information system.

\begin{tabular}{l|l|l|l|l|l}
\hline & $\begin{array}{c}\text { Very } \\
\text { poor }\end{array}$ & Poor & Fair & Good & $\begin{array}{c}\text { Very } \\
\text { good }\end{array}$ \\
\hline accessibility & & & & & \\
\hline searchability & & & & & \\
\hline accuracy & & & & & \\
\hline relevance & & & & & \\
\hline portability & & & & & \\
\hline archivability & & & & & \\
\hline movability & & & & & \\
\hline
\end{tabular}

Please evaluate the below-mentioned features of technical support of information system in your company.

\begin{tabular}{l|l|l|l|l|l}
\hline & $\begin{array}{l}\text { Very } \\
\text { poor }\end{array}$ & Poor & Fair & Good & $\begin{array}{c}\text { Very } \\
\text { good }\end{array}$ \\
\hline assurance & & & & & \\
\hline empathy & & & & & \\
\hline responsiveness & & & & & \\
\hline fail rate & & & & & \\
\hline quality & & & & & \\
\hline availability & & & & & \\
\hline
\end{tabular}

